\title{
Liver disease associated with intestinal failure in the small bowel syndrome ${ }^{1}$
}

\author{
Doença hepática associada à falência intestinal na síndrome do intestino curto
}

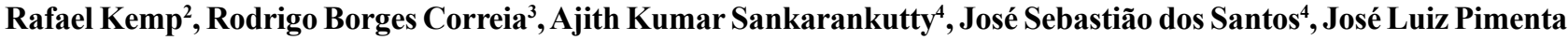 \\ Módena $^{4}$, Enio David Mente ${ }^{5}$, Orlando de Castro e Silva ${ }^{5}$ \\ 1. Work performed in the Liver Transplantation Unit of Division of Gastroenterology of the Department of Surgery and Anatomy, \\ Ribeirão Preto Faculty of Medicine - University of São Paulo (FMRP - USP), Brazil. \\ 2. MD of Division of Gastroenterology of the Department of Surgery and Anatomy, (FMRP-USP), Brazil. \\ 3. Fellow PhD degree of Division of Gastroenterology of the Department of Surgery and Anatomy, (FMRP-USP), Brazil. \\ 4. PhD, Professor of Division of Gastroenterology of the Department of Surgery and Anatomy, (FMRP-USP), Brazil. \\ 5. PhD, Assistant of Division of Gastroenterology of the Department of Surgery and Anatomy,(FMRP-USP), Brazil \\ 6. Full Professor, Head of Division of Gastroenterology of the Department of Surgery and Anatomy, (FMRP-USP), Brazil.
}

\begin{abstract}
The introduction of the Total Parenteral Nutrition (TPN) has given rise to a new hope in the treatment of intestinal failure (LF) associated with the Short Bowel Syndrome (SBS). However, together with the TPN and the increase of survival of these patients, new problems and questions have emerged, as well as new therapeutical procedures. Taking into consideration this emerging reality, this paper has the purpose to undertake a review of current concepts and available treatments for patients with IF associated-liver disease. Although TPN provides an increase of survival of patients with intestinal failure, it is a potential source of complication such as: septicemia, hyperglycemia, venous thrombosis and liver disease. There are several hypothesis conceived to explain the liver disease associated to intestinal failure, however the only definite treatment as a potential to reverse the non-cirrhotic liver disease is the small intestine transplantation. Despite indications for intestine transplantation are not entirely defined in literature, the trend is its early indication in high-risk patients, preserving the liver integrity and preventing the eventual need of both liver and intestine transplantations altogether.
\end{abstract}

Key words: Short Bowel Syndrome. Intestinal Transplantation. Total Parenteral Nutrition. Intestinal Failure. Liver Disease.

\section{RESUMO}

A introdução da Nutrição Parenteral Total (NPT) despertou uma nova esperança para o tratamento da falência intestina (FI) associada a Síndrome do Intestino Curto (SIC). No entanto, junto com a NPT e o aumento da sobrevida destes pacientes, novos problemas e perguntas emergiram, assim como novas terapêuticas. Tendo em vista esta realidade emergente, o intuito deste artigo é realizar uma revisão dos conceitos atuais e dos tratamentos disponíveis para pacientes com doença hepática associada a FI. A NPT apesar de proporcionar aumento da sobrevida nos pacientes com falência intestinal é fonte potencial de complicações, como: septicemia, hiperglicemia, trombose venosa e doença hepática. Diversas são as hipóteses aventadas para explicar a doença hepática associada a falência intestinal, no entanto, o único tratamento definitivo, com potencial para reverter à doença hepática não cirrótica, é o transplante de intestino delgado. Apesar das indicações do transplante de intestino não estarem totalmente definidas na literatura, a tendência é indicá-lo precocemente em pacientes de alto risco, preservando a integridade hepática e prevenindo a eventual necessidade de transplante de fígado e intestino combinados.

Descritores: Síndrome de Intestino Curto.Transplante de Intestino Delgado. Nutrição Parenteral Total. Falência Intestinal. Doença Hepática.

\section{Introduction}

Short Bowel Syndrome (SBS) is defined in adults when the small intestine length is shorter than $200 \mathrm{~cm}^{1}$. SBS is characterized by weight loss, malnutrition, steatorrhea and acid diarrhea due to the loss of absorptive surface and reduction of intestinal transit time. Other findings associated with SBS include nephrolithiasis, cholelithiasis and gastric hyper secretion ${ }^{2}$. SBS etiology can be divided both into acquired and congenital types. Among the causes of acquired disorders we can mention multiple or large enterectomies due to vascular catastrophes that involved thrombosis and emboly of the mesenteric artery, Crohn's Disease, volvo, trauma and tumor resections. Infants may be born with congenital jejunal or ileal atresia, and the leading causes of SBS in the pediatric population are necrosing enterocolitis, gastroschisis, intestinal malrotation, volvulus and extensive aganglionosis ${ }^{2}$. 
Removal of large segments of the small intestine (SI) causes the loss of intestinal absorptive surface and/or reduction of intestinal transit time, which results in malnutrition, bad absorption and metabolic disturbances. SBS severity depends on the remanescent intestine length: if the remanescent intestine is longer than $100 \mathrm{~cm}$, the patients are likely to tolerate oral feeding in a short period of time. If the length is between 50 to $100 \mathrm{~cm}$, the patient will need parenteral nutrition (PN) for a short period of time and will probably resume regular oral nutrition alone. Patients with a very short intestinal remnants $(<50 \mathrm{~cm})$ in general will develop intestinal failure (IF) ${ }^{3}$. IF occurs when the gastrointestinal tract (GIT) is unable to keep the nutritional state without the specific nutritional support, either enteral or parenteral. Not every patient with SBS has sufficient loss of the functional capacity to develop permanent intestinal failure. Some factors are related to a higher risk of IF development such as duodenostomy or jejunoileal anastomosis and less than $35 \mathrm{~cm}$ of residual small intestine, jejunocolic or ileocolic anastomosis and less than $60 \mathrm{~cm}$ of residual small intestine, or end jejunostomy with less than $115 \mathrm{~cm}$ of remanescent small intestine ${ }^{1}$. Generally these patients are considered candidates to permanent parenteral nutrition or intestinal transplantation, because the remanescent intestine length is insufficient to develop the structural and functional adaptation ${ }^{3}$. We shall highlight that IF does not have as its unique factor the intestinal loss. In the presence of gastric and pancreatic disorders, in their resections, or even in non-surgical losses of abortive surface we will have a picture of bad absorption that, when it is serious, leads to IF, characterized as functional SBS. After resection, the remanescent intestine becomes hypertrophied and its absorptive function is more efficient, which allows its adaptation.

CHART 1 - Causes of intestinal failure

\begin{tabular}{|l|l|}
\hline Functional & Non functional \\
Mucosal disease & - Ileal or jejunal atresia \\
- Celiac disease & - Gastroschisis \\
- Wipple's disease & - Intestinal ressections \\
- lymphoma & (ileal resection, ileocolic \\
- Ulcerative jejunoileitis & ressection ) \\
- Abetalipoproteinemia & - End jejunostomy \\
Small intestine disease & - Extensive Aganglionosis \\
- Dysmotility & \\
- Radiation injury and & \\
$\quad$ chemotherapy & \\
- Inflammatory bowel & \\
$\quad$ disease & \\
- Infections (eg, HIV) & \\
- Autoimmune disease & \\
- Neoplasms & \\
Gut bypass & \\
- Intestinal fistulae & \\
- Surgical Bypass & \\
Mal digestion & \\
- Gastric resection & \\
- Pancreatic resection & \\
\hline
\end{tabular}

There is the desacceleration of intestinal transit, increase of villus diameter and height that results in absorption increase, in a process that last about 1 to 2 years. The presence or absence of the colon and ileocecal valve, location (jejunum versus ileum), health and length of residual bowel mucosa blood flow, patient age and comorbid conditions such as Crohn's disease, radiation enteritis, carcinoma and pseudo-obstruction are influencing factors in the adaptation process and clinical outcome ${ }^{1}$. Animalmodel studies suggest that the adaptation process is complex and influenced by several endogenous hormones such as: enteroglucagon, glucagons peptide 2, growth hormone, epidermal growth factor, cholecystokinin, insuline, gastrin and neuroten $\sin ^{1}$. Another important factor in these patients is the presence or absence of colon, because it might become a significant digestive organ responsible for water, sodium, some aminoacids and short-chain fatty acids absorption that are important during the adaptation process $^{1}$. The introduction of PN in the 60s changed the handling of patients with IF and provided for the first time long-term survival in patients with large intestinal losses. Unfortunately, $\mathrm{PN}$ is a potential provoking source of complications, being the most important septicemia, hyperglycemy, venous thrombosis and liver disease attributed to the unphysiological nature of the endovenous nutrition, since the nutrients are injected into the organism in different directions and at different rates ${ }^{4}$. The term "parenteral nutrition failure" was recently adopted to describe a situation in which PN complications become lifethreatening, including complications such as loss of venous access by progressive central venous thrombosis, development of irreversible liver fibrosis or cirrhosis, recurrent episodes of septicemias or fungemies, which results in intensive care unit admission. The importance of this definition is based on the indication of small bowel or multi-visceral transplantation in patients carrying this syndrome ${ }^{4}$. Perhaps the most puzzling PN complication is the chronic liver disease and liver failure. This syndrome develops in 40 to $60 \%$ of children who require prolonged $\mathrm{PN}$ and in 15 to $40 \%$ of adults under home PN. The clinical spectrum includes hepatic steatosis, cholestasis, cholelithiasis, liver fibrosis and more rarely progression to biliary cirrhosis, development of portal hypertension and liver failure. Although liver dysfunction evidenced by enzymatic abnormalities is common, the progression to cirrhosis and liver failure is less frequent, badly understood and uniformly lethal if there are no combined liver and intestine transplantations ${ }^{5}$. Hepatic dysfunction secundary to intestinal failure differs in adults and children. Cholestasis occurs in 40 to $60 \%$ of children, steatosis in 40 to $55 \%$ of adults, biliary sludge and cholelithiasis develop in both cases. The etiology is multifactorial and is cited in following Chart $^{5}$. In adults, cholestasis is related to residual intestine length $(<50 \mathrm{~cm})$, probably because of the difficulty of intestinal adaptation and sufficient enteral feeding in such a short gut leading to long term dependency on PN. There is the occurrence of interruption of entero-hepatic circulation of biliary salts, causing an abnormal metabolism of biliary acids which provides a bacterial translocations and systemic sepsis. Prospective studies related the presence of cholestasis in adults with permanent intestinal 
failure to intake of lipids greater than $1 \mathrm{~g} / \mathrm{kg} /$ day in PN. The mechanism is uncertain, but it may be associated with the activation of macrophages caused by excess of W6 polyunsaturated fatty acids, which causes an accumulation of hepatic phospholipids and/or phytosterols ${ }^{5}$.

CHART 2 - Etiology of liver disease associated with intestinal failure

$$
\begin{aligned}
& \text { - Prematurity and low birth weight } \\
& \text { - Parenteral nutrition (PN) duration } \\
& \text { - Length of bowel remnant } \\
& \text { - Reduced enterohepatic circulation } \\
& \text { - Lack of enteral nutrition } \\
& \text { - Recurrent sepsis } \\
& \text { - Toxic components of PN (peroxides) } \\
& \text { - Protein under nutrition } \\
& \text { - Deficiency of essential fatty acids and chlorine } \\
& \text { - Excess of dextrosis or lipidic emulsion }(>1 \mathrm{~g} / \mathrm{kg} / \mathrm{day})
\end{aligned}
$$

Gastrointestinal hormones levels such as gastrin, motilin, glucose-dependent insulinotrophic polypeptides, secretin, pancreatic polypeptide, glucagon and vasoactive intestinal peptides are reduced in patients with exclusive PN. This leads to the decrease of gallbladder contractibility and intestinal stasis. Intestinal stasis is related to the bacterial growth, bacterial translocation, sepsis (which exacerbate cholestasis in children) and the production of lithocholic acid (that turned to be toxic in rat liver) $)^{5,3}$. Cholecystokinin reduction influences the size and the contraction ability of the gallbladder, thus making up biliary sludge. It is possible that fasting is able to reduce the biliary salts pool and bile formation influencing the gallbladder dysmotility and the formation of biliary sludge ${ }^{5}$. Liver disease associated with IF is related both to deficiency and to excess of amino acids or lipids in PN solutions. Taurine and cysteine deficiency is associated with hepatotoxicity in neonates. Choline deficiency may exacerbate hepatic steatosis both in children and adults. In a pilot study, the addition of $2 \mathrm{~g}$ choline chloride reduced steatosis in adults, evidenced by the normalization of hepatic transaminases and by computed tomography scores ${ }^{5}$. Recent studies reported the effects of manganese toxicity in prolonged PN. Because manganese is excreted in the bile its toxic effect is exacerbated in cholestasis, then its monitoring is important in patients with liver disease associated with IF. There is evidence that lipidic emulsions induce both cholestasis and steatosis . The excess of lipidic calories (lipid overlood syndrome) leads to hepatic steatosis, hyperlipidemia and thrombocytopenia. Cavicchi et al showed that cholestasis in adults is related to usage of more than $1 \mathrm{~g} / \mathrm{kg} / \mathrm{day}$ of lipids, and the damage mechanism is the direct effect of lipids in the hepatocytes, accumulation of phospholipids or phytosterols, or the production of inflammatory cytokines $^{5}$. The incidence of biliary sludge increases with the PN duration increases of $6 \%$ within 3 weeks up to $100 \%$ within 6 to 13 weeks, as well as the formation of gallstone, particularly in patients who have suffered ileal resections. Stasis of gallbladder may be prevented through the administration of cholecystokinin or by endogenous stimulation of cholecystokinin liberation by means of amino acids infusion or enteral nutrition $(5 \text { to } 10 \mathrm{ml} / \mathrm{h})^{5}$.

\section{Clinical Aspects}

Early liver dysfunction is asymptomatic, but jaundice is an obvious sign of cholestasis and fluctuations in serum bilirrubines may be related to septical episodes. The most frequent hepatic abnormalities observed are elevations in lactate dehydrogenase (DHL) levels, alkaline phosphatase (FA) 2 to 10 times the normal and total bilirrubin (BT) 5 to 22 times the normal. These patients also showed microscopic evidence of cholestasis. Albumin levels lower than $2 \mathrm{~g} / \mathrm{dl}$ were found in patients with $\mathrm{PN}$-induced cholestasis. Persistent elevations of serum bilirrubin higher than $12 \mathrm{mg} /$ $\mathrm{dl}$ represent a bad prognosis. In a study, 6 out of 42 patients who had developed end-stage liver disease with home PN use died within 10 months from the first episode of bilirrubin elevation ${ }^{5,6}$. PN-induced cholestasis, in adults, does not appear until weeks or months of infusion have gone by, and the clinical manifestations are not usual until significant liver dysfunction is developed with hepatomegaly. Jaundice is a late sign, but abnormal levels of hepatic transaminases appear in $39 \%$ of patients in long-term $\mathrm{PN}^{4,5,6}$.

\section{Histology}

Histopathological changes of IF associated with cholestasis range from hepatic steatosis to biliary cirrhosis. Hepatic steatosis is more common in adults and may develop without evidence of inflammation, cholestasis or hepatic cellular necrosis. Hepatic steatosis is less common in children who most frequently show centrilobular cholestasis, portal inflammation and necrosis with or without fatty infiltration. More advanced liver disease includes portal fibrosis (100\%), pericellular fibrosis (95\%), and bile ductular proliferation (90\%). Pigmented Kupffer's cells $(81 \%)$ and portal bridging $(86 \%)$ are prominent features. Cholestasis is not always present and biliary cirrhosis has a late development, leading to death within 6 months $^{5}$.

\section{Treatment}

In order to illustrate the evolution of the liver disease associated with PN, a recent review of 2 programs in Paris, which assessed 90 patients in home PN between 1985 and 1996 , showed that $65 \%$ had developed chronic biochemical cholestasis and $42 \%$ extended portal fibrosis or cirrhosis. End-stage liver disease was the death cause of $22 \%$ of the patients, being the remanescent intestine size and PN dependence the most important factor for the development of the liver disease ${ }^{4}$. Due to this picture, the early introduction of measures to avoid or delay the evolution of the end-stage liver disease is of paramount importance. Liver disease associated with IF is potentially reversible, with normal tests of hepatic functions within 1 month when the enteral nutrition is introduced and $\mathrm{PN}$ is interrupted, before 
the development of severe fibrosis or cirrhosis. In many children and adults this is not possible. Prevention and treatment of liver disease associated with IF include certain measures, though none of them has proved its effectiveness $^{5,6}$.

CHART 3 - Prevention and Treatment of hepatic disease associated with IF
Stimulate enteral feeding
Reduce PN duration
Reduce bacteria overgrowth through oral
econtamination of GT, probiotic fibersnd glutamine
Central line care
Ursodeoxycholic acid 15 to $20 \mathrm{mg} / \mathrm{kg} /$ day

The introduction of small amounts of enteral nutrition will improve the biliary dynamics, diminish the gallbladder size and will improve the biliary flow; therefore there will be the cholestasis improvement. Other strategies include the decrease of bacteria overgrowth through the introduction of fibers in the enteral nutrition, for these can diminish the bacterial translocation, and accordingly episodes of systemic sepsis ${ }^{5,6}$. The addition of glutamine to PN solutions may reduce the effect of septic episodes in the liver function, because glutamine reverses the inhibition of the hepatocyte mitochondrial metabolism noted in rat endotexemia. Glutamine has also a protective effect against the hepatic dysfunction related to PN by the increase of the intestinal immunity. This reduces the intestinal hypoplasia and prevents immunoglobulin A depletion, and has also an effect in the reduction of the intestinal permeability and thus the bacterial translocation in rats ${ }^{(4,5)}$. Oral administration of Sacchromyces boulardii, non-pathogenic flora, may reduce bacterial translocation due to the increase of immunoglobulin A secretion and bacterial overgrowth reduction. Another useful strategy is the reduction of the daily PN duration or the use of cyclic infusion. If there is a severe cholestasis, restriction of lipid intake and control of the manganese and copper levels are important $t^{4,5}$. The most important strategy is the prevention of sepsis through multiple multidisciplinary aseptic cares in the management of central catheters ${ }^{(5)}$. In order to increase the biliary flow and reduce the biliary sludge formation, it is advantageous the use of oral ursodeoxycholic acid that is commonly prescribed, though there is not a clear evidence of its effectiveness. However, in a prospective adult study in $\mathrm{PN}$, the ursodeoxycholic acid showed improvement in the tests of hepatic function ${ }^{5,6}$.

\section{Small bowel transplantation}

With improvements of both surgical and immunemodulation techniques, small bowel transplantation (SBT) became a viable alternative to home $\mathrm{PN}$, with survival rates of 1 year for both, host and graft, of around $90 \%$. The fascinating observation that isolated SBT has the potential to reverse non-cirrhotic liver disease is encouraging us to propose SBT of risk patients, those with less than $50 \mathrm{~cm}$ of remanescent intestine, with the aim of preserving the liver health and prevent the eventual need of combined transplantation of liver and small bowel $^{4}$. SBT is considered the only definitive treatment for patients with SBS who failed in the development of intestinal adaptation. Although SBT indications are not yet completely standardized, there is already a trend to indicate it before the development of liver failure. Generally, mortality and morbidity are higher in patients with SBS without colon, and its reason is still unknown. Patients with remanescent intestine less than $50 \mathrm{~cm}$ long and colectomized show SBT indication, being listed as soon as they are stable, using $\mathrm{PN}$ as a bridge ${ }^{3}$. Those with less than $50 \mathrm{~cm}$ long remanescent intestine and presence of colon are put under PN, and as soon as possible they are introduced to special diet for small bowel, which, if tolerated, is added to an oral supplementation and the $\mathrm{PN}$ is interrupted. Food is given more often than 10 times a day, solid and liquid stuff are separately administered if the intestinal transit time is fast, more than 2 liters of water is given per day, avoiding the administration of food that contain lactulose, oxalate, liquids containing caffeine and artificial sweeteners. If there is no adaptation of patients to the diet, SBT is indicated $^{(3,7)}$. Patients with remanescent intestine between $50-100 \mathrm{~cm}$ associated with colectomy or those whose colon has been preserved follow the above-mentioned program, but the latter ones will hardly ever be candidates to SBT ${ }^{(3,7)}$. Patients subjected to enterectomy, with intestinal remanescent longer than $100 \mathrm{~cm}$, with or without associated colectomy will develop intestinal adaptation and tolerance to oral nourishment in a short period of time $e^{3,7}$.

\section{General considerations}

The management of patients with IF associated with small bowel syndrome represents a threat for the modern clinical surgery. The increase of survival for these patients due to new techniques of total parenteral nutrition (TPN), gave rise to new barriers, many of them, until now limiting the therapeutic options in patients with IF. Chronic hepatic disease associated with TPN and with IF appeared as one of the most puzzling and hard-management complications in patients with SBS. We ask an obvious question in an attempt to understand this new problem: what does the intestine provide that is necessary for the liver health? The answer is: NUTRIENTS. It is not by chance that the liver is strategically positioned to receive first-hand the nutrients, after the food digestion, many of which are removed after their first passage through this organ. The new pathway of nutrients infusion introduced by the TPN made it possible to increase the survival rate of patients with IF, though, on the other hand it limits the natural hepatic nutrition. So far, there are more doubts than answers, but with the recent introduction of new therapeutic procedures, arises a new small hope in the preservation of the liver health in patients under long TPN, and perhaps, there is the need 
of more researches addressing the restoration of the normal physiology of nourishment, digestion and nutrient absorption for which the human organism was designed. Considering the physiological pathway of nutrition access and the preservation of the small bowel health the only definitive and available treatment so far is the small bowel transplantation, and although its indication is not completely defined in the literature, there is the trend of its early realization in patients with high risk of developing cirrhosis and liver failure that is invariably lethal in the evolution of IF associated with SBS.

\section{References}

1. Buchmam AL. Etiology and initial management of shor bowel sydrome. Gastroenterology. 2006;130:S5-S15.

2. Muiesan P, Dhawan A, Novelli M, Mielli-Vergani G, Rela $\mathrm{M}$, Heaton N. Isolated liver Transpalnt and sequential small bowel transplantation for intestinal failure and related liver disease in chindren. Transplantation. 2000;69:2323-6.

3. Atalay F, Ozcay N, Gundogdu H, Orug T, Gungor A. Akoglu M. Evaluation of the outcomes of short bowel síndrome and indication for intestinal transplantation. Transpl Proc. 2003;35:3054-6.

4. O‘Keefe SJ. Bacterial overgrowth and liver complications in short bowel intestinal failure patients. Gastroenterology. 2006;130:S67-9.

5. Kelly DA. Intestinal failure-associated liver disease: What do we know today?. Gastroenterology. 2006;130:S70-7.

6. Burstyne M, Jensen GL. Abnormal liver functions as a result of total parenteral nutrition in a patient with shortbowel syndrome. Nutrition. 2000;16:1090-2.

7. Jeejeebhoy KN. Manegement of short bowel syndrome: Avoidance of total parenteral nutrition. Gastroenterology. 2006;130:S60-6.

\section{Correspondence:}

Orlando de Castro e Silva Jr.

Rua Campos Salles, 809 - $9^{\circ}$ andar. CEP: 14015-110

Centro, Ribeirão Preto - SP - Brazil.

Email: orlandocsj@hotmail.com
Conflict of interest: none Financial source: CNPq and FAPESP

\section{How to cite this article:}

Kemp R, Correia RB, Sankarankutty AK, Santos JS, Módena JLP, Mente ED, Castro e Silva O. Liver disease associated with intestinal failure in the small bowel syndrome. Acta Cir Bras. [serial on the Internet] 2006;21 Suppl 1. Available from URL: http://www.scielo.br/acb 